\title{
Perioperative Predictive Factors Following Splenectomy for Complete Remission of Immune Thrombocytopenic Purpura
}

\author{
Ieva Vidmane-Ozola*/***, Viesturs Boka*/**, Egils Cunskis*, Janis Breikss*, Sandra Lejniece*/***, Uldis Teibe***** \\ * Riga Eastern Clinical University Hospital, Clinic "Linezers", Latvia \\ ** Riga Stradins University, Department of Surgical Diseases, Latvia \\ *** Riga Stradins University, Department of Internal Diseases, Latvia \\ $* * * *$ Riga Stradins University, Department of Continuous Education, Latvia \\ $* * * * *$ Riga Stradins University, Department of Physics, Latvia
}

\begin{abstract}
Summary
Introduction. Immune thrombocytopenic purpura (ITP) is one of the most commonly known and widely researched haematological diseases. ITP manifests as decrease in platelet count of various degrees, which can even cause fatal bleeding from $0.4-13 \%$ annually. Glucocorticoids (GC) and intravenous immunoglobulin (IgG) are used as the first line of treatment, 20-50\% of drug therapy is ineffective and splenectomy is "the second stage" of treatment.

Various sources of literature mention the range of ITP remission following splenectomy from $49-93 \%$. Current studies are looking for prognostic factors, which would ensure complete ITP remission following splenectomy.

Aim of the Study. To analyse possible perioperative prognostic factors in ITP patients for achieving remission following splenectomy. Materials and methods. The retrospective study included 13 patients diagnosed with immune thrombocytopenic purpura (ITP), who underwent surgery in the period from 2002 to 2009 at the Riga Eastern Clinical University Hospital "Linezers". From laboratory tests - full blood-count 1 - 2 days before the operation, on the 5th - 7th day following the operation, 1 month after the operation, one year after the operation and during the last follow-up found in the patient's out-patient file. The size of the spleen before the surgery was determined by ultrasonography.

The access to the abdominal cavity and the spleen - conventional or laparoscopic surgery, the duration of the operation, perioperative blood loss, post-operative complications and the patient's day of discharge following the surgery was analysed.

Results. In the period from January 2002 to January 2009 at RECUH clinic "Linezers" 13 ITP patients underwent surgery. As to the gender the average age for both genders was similar (men $39.0 \pm 14.1$ and women $39.0 \pm 16.0$ ). The mean value of the duration of the disease in women $(8.0 \pm 9.0$ months $)$ and men $(68.1 \pm 58.7$ months) has a statistically significant difference, using the independent pair selection t-test $(t=2.38 ; p=0.047)$. In one US case and in one CT case accessory spleens were detected. The preoperative mean value of PLT count had increased in a statistically significant way in accordance with the independent pair selection t-test $(t=3.087 ; p=0.009)$, and in accordance with Wilcoxon signed-rank test $(z=2,202 ; p=0,028)$ compared to the mean value of PLT count, which was detected during the last follow-up visit on average $35.9 \pm 35.9$ months after the surgery. Analysis of variance (ANOVA) shows that the average age of cured patients

$34.6 \pm 9.8$ is statistically less significant than for those patients, who continue treatment and whose disease has transformed $(F=$ 7.327; $p=0.011)$.

Conclusions. The performed research allows concluding that the decisive factors in successful ITP outcome after the operation are the following: 1) in patients, who have undergone the operation in a relatively younger age (34.6 \pm 9.8 years) the disease outcome is more successful during the follow - up period $-35.9 \pm 35.9$ months $(F=7.327 ; p=0.011)$; 2$)$ the visualisation and removal of the accessory spleen decreases the probability of relapse.
\end{abstract}

Key words: ITP, splenectomy, laparoscopic splenectomy, accessory spleens.

\section{INTRODUCTION}

Immune thrombocytopenic purpura (ITP) is one of the most commonly known and widely researched haematological diseases. Its incidence is 4.5/100 000 among men and 7.4/100 000 among women (8).

In cases of ITP anti-bodies bind with antigens on platelet surface, causing increased loss of reticuloendothelial system cells in the spleen, to a lesser extent - in the liver and bone marrow. Thus, ITP manifests as decrease in platelet count of various degrees, which can even cause fatal bleeding from $0.4-13 \%$ annually (17) .
The treatment of ITP is predominantly targeted at restoring the platelet count and decreasing the risk of bleeding. Glucocorticoids (GC) and intravenous immunoglobulin (IgG) are used as the first line of treatment, the second line of treatment is splenectomy. In case of post-splenectomy refractory ITP immunosuppressive therapy (IS) (Cyclosporine, Azatioprin) vinca alkaloids (Vinblastine, Vincristine), Danazol, thrombopoietin analogues (Eltrombopag), intravenous anti-D antibody therapy, monoclonal antibodies antiCD20-Rituximab are used. Currently 
studies on using GC and immunoglobulin in treating ITP have not been randomized (4). Similarly, research on the use of anti-D antibodies and antiCD20 in the treatment of ITP are still ongoing $(1,1)$.

$20-50 \%$ of drug therapy is ineffective and splenectomy is "the second stage" of treatment $(3,4,12,17,21)$. Splenectomy has a dual meaning in the treatment of ITP - elimination of the source producing anti-platelet bodies and elimination of the main site of platelet destruction (1).

For the first time splenectomy in the treatment of ITP was described by Kaznelson in 1916 (3). With the development of modern and minimally invasive surgical technologies, in 1991 Delaitre and Maignien introduced laparoscopic splenectomy (LS) in the treatment of haematological diseases (19). ITP is the most frequent indication for LS because of the unchanged or slightly increased size of the spleen. Several studies have proven that LS is a safe and effective method for treating ITP, due to shorter period of hospitalization, quicker return to active life, smaller post-operative pain and number of complications, and better cosmetic effect compared to conventional splenectomy (CS). The surgical technique has no impact upon ITP outcome following the operation $(3,7,12,14,16)$. Various sources of literature mention the range of ITP remission following splenectomy from $49-93 \%(3,9,14,22,23)$. Current studies are looking for prognostic factors, which would ensure complete ITP remission following splenectomy $(2,3,8,9,13,17,20,23)$.

\section{AIM OF THE STUDY}

To analyse possible perioperative prognostic factors in ITP patients for achieving remission following splenectomy.

\section{MATERIALS AND METHODS}

The retrospective study included 13 patients diagnosed with immune thrombocytopenic purpura (ITP), who underwent surgery in the period from 2002 to 2009 at the Riga Eastern Clinical University Hospital "Linezers". Patients' out-patient files and medical records were analysed.

From laboratory tests - full blood-count $1-2$ days before the operation, on the $5^{\text {th }}-7^{\text {th }}$ day following the operation, 1 month after the operation, one year after the operation and during the last follow-up found in the patient's out-patient file.

To evaluate the coagulogram the activated partial thromboplastine time (APTT), prothrombine index (PI) and the bleeding time according to Duke's method was detected. All patients underwent bone marrow biopsy to exclude primary haematological disease.

The size of the spleen before the surgery was determined by ultrasonography, following the splenectomy the spleen was weighed on scales and its histological examination was performed.

The use of platelet mass (PLTM), erythrocyte mass (EM) and fresh frozen plasma (FFP) during the perioperative period was analysed. The patient's physical condition was assessed in accordance with the generally recognised ASA (American Society of Anesthesiologists) classification.

The access to the abdominal cavity and the spleen conventional or laparoscopic surgery, the duration of the operation, perioperative blood loss, post-operative complications and the patient's day of discharge following the surgery was analysed.

All operations were performed under endothracheal anaesthesia, during the surgery nasogastral tube was inserted, in all patients undergoing CS Foley type urinary bladder catheter No.18 was inserted. To ensure perioperative antibacterial prevention measures, all patients during the initial anaesthesia received 2 grams of a third generation cephalosporin antibacterial drug cefoperazone.

When midline laparatomy is performed, the patient is supine with arched lumbar part, if a $\mathrm{n}$ incision under the ribs is performed, then the patient has right lateral position with arched rib arc.

During the laparoscopic operation the patient has a right semi-lateral position in an angle of $45^{\circ}$ with arched lumbar part. Initially the abdominal cavity is punctured with Varesa needle in the middle of the line connecting the navel with the middle point situated immediately behind the rib arc and filled with $\mathrm{CO} 2$ till $12 \mathrm{mmHg}$ (Fig. 1, A). After that a $10 \mathrm{~mm}$ optical trocar is placed $\left(30^{\circ}\right.$ slanted optics- Olympus optical, Tokyo, Japan are used). Following that working trocars are placed. One $10 \mathrm{~mm}$ trocar is placed in the epigastrium on the left to the hepatic cord (Fig.l, B), the second $10 \mathrm{~mm}$ trocar is placed along linea axillaris anterior below the rib arc (Fig. 1, C), a $12 \mathrm{~mm}$ trocar is placed along linea medioclavicularis sinistra $2-3 \mathrm{~cm}$ below the rib arc (Fig. 1, D). All trocar sites can be diverted, depending upon the size of the spleen and its position in the abdominal cavity (Fig.1).

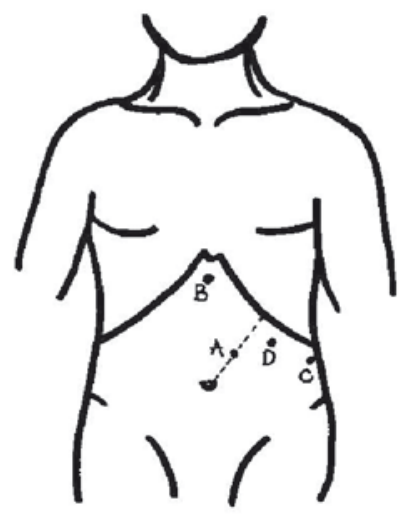

Fig. 1 The port sites of patients undergoing laparoscopic splenectomy

During conventional surgery intact spleen is removed from the abdominal cavity. During laparoscopic surgery the spleen is placed in an endoscopic bag (EndoBag) and then is removed, by performing a minilparatomy incision $\sim 7 \mathrm{~cm}$ long, joining the site of the $10 \mathrm{~mm}$ trocar, which is placed on linea axillaris anterior below the rib arc 
with the trocar placed on linea medioclavicularis sinistra 2 $3 \mathrm{~cm}$ below the rib arc. After the surgery the abdominal cavity is closed "layer by layer".A drain is placed in the site of the spleen at the end of both conventional and laparoscopic operation.

Following the surgery all patients are monitored at the intensive care unit (ICU).

All patients who underwent surgery received identical postoperative antibacterial therapy. All patients were vaccinated with Pneumo - 23 .

This study is a part of Doctoral Thesis and the study application are going to be approved to Ethics commission of the Rīga Stradiņš University.

\section{RESULTS}

In the period from January 2002 to January 2009 at RECUH clinic "Linezers" 13 ITP patients underwent surgery. See Table 1 for patients' characteristics. The study includes 8 women and 5 men, the average age $39 \pm$ 14.2 , the youngest patient was an 18 years old woman, the oldest - a 66 years old man. As to the gender the average age for both genders was similar (men $39.0 \pm$ 14.1 and women $39.0 \pm 16.0$ ).

The average duration of the disease prior to the surgery was $45 \pm 54.4$ months. The shortest period from setting the diagnosis to the surgery was 1 month, the longest 156 months. The mean value of the duration of the disease in women $(8.0 \pm 9.0$ months $)$ and men $(68.1 \pm$ 58.7 months) has a statistically significant difference, using the independent pair selection $\mathrm{t}-$ test $(\mathrm{t}=2.38 ; \mathrm{p}=$ 0.047).

Prior to the surgery $2(15.4 \%)$ patients received only GC therapy, 5 patients $(38.5 \%)$ received GC and IS therapy, in 5 cases $(38.5 \%$ ) GC and IgG was applied. One patient, for whom the duration of the disease prior to the surgery was 7 months, had received both GC and IS, as well as IgG therapy $(7.7 \%)$.

\section{Table 1. Patients' characteristics}

\begin{tabular}{|c|c|c|}
\hline \multicolumn{2}{|l|}{ Total } & $13(\mathrm{~N})$ \\
\hline \multicolumn{2}{|l|}{ Gender: female/ male: } & $8 / 5$ \\
\hline \multicolumn{2}{|c|}{ Average age (years \pm SD) } & $39 \pm 14.2$ \\
\hline \multicolumn{2}{|c|}{ Maximum fluctuation of the average age } & $18-66$ \\
\hline \multicolumn{2}{|c|}{$\begin{array}{l}\text { Duration of the disease prior to the } \\
\text { surgery (months } \pm \text { SD) }\end{array}$} & $45,0 \pm 54.4$ \\
\hline \multicolumn{2}{|c|}{$\begin{array}{l}\text { Maximum fluctuation of the duration of } \\
\text { the disease prior to the surgery }\end{array}$} & $1-156$ \\
\hline \multirow{4}{*}{$\begin{array}{l}\text { Therapy received up } \\
\text { to the surgery }\end{array}$} & GC & 2 \\
\hline & $\mathrm{GC}+\mathrm{IgG}$ & 5 \\
\hline & GC + IS & 5 \\
\hline & GC + IS + IgG & 1 \\
\hline \multirow{3}{*}{$\begin{array}{l}\text { The size of the spleen } \\
\text { prior the operation } \\
(\mathrm{cm})\end{array}$} & Average \pm SD & $10.7 \pm 1.6$ \\
\hline & $\begin{array}{l}\text { Maximum } \\
\text { fluctuation }\end{array}$ & $8.3-13$ \\
\hline & $\begin{array}{l}\text { Auxiliary spleen ( } \\
\text { cases ) }\end{array}$ & 2 \\
\hline \multicolumn{2}{|l|}{ ASA I/II/II/IV } & $1 / 9 / 3 / 0$ \\
\hline
\end{tabular}

\begin{tabular}{|l|l|c|}
\hline \multicolumn{2}{|l|}{ Day of discharge after the surgery } & $6.8 \pm 2.1$ \\
\hline \multicolumn{2}{|l|}{ Post-operative follow-up period } & $35.9 \pm 35.9$ \\
\hline $\begin{array}{l}\text { Disease outcome } \\
\text { following the } \\
\text { operation }\end{array}$ & Remission & 11 \\
\hline & Continues therapy & 1 \\
\hline & $\begin{array}{l}\text { Transformation of } \\
\text { the disease }\end{array}$ & 1 \\
\hline
\end{tabular}

Fig. 1.

The average platelet count during the follow-up period

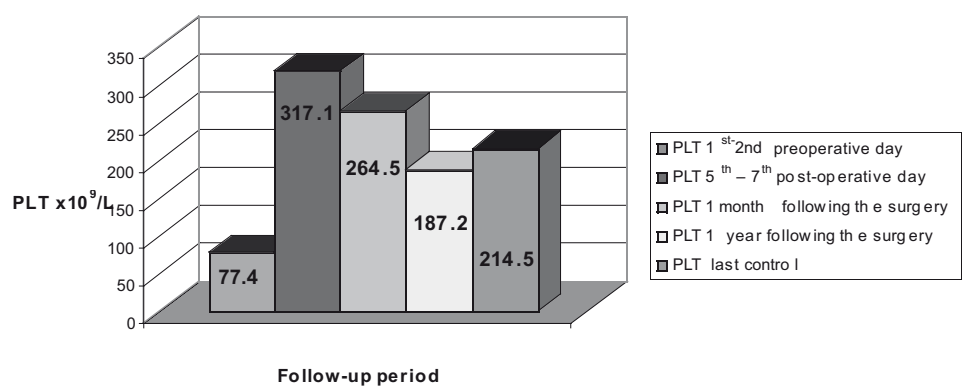

Prior to the operation all patients underwent ultrasonography (US), in 5 cases - computer tomography (CT) examination with $\mathrm{i} / \mathrm{v}$ infused radiopaque. The average size of the spleen was $10.7 \pm 1.6 \mathrm{~cm}$. In one US case and in one CT case accessory spleens were detected, which were removed to prevent failure of ITP treatment following the surgery.

Changes in platelet count (PLT) in the perioperative period are shown in Figure 1. Prior to the operation severe thrombocytopenia (PLT $<50$ x $10^{9} / \mathrm{L}$ ) was observed in 6 cases. In these cases the platelet count was adjusted a week before the operation with platelet mass transfusions (6 and 3 units). Thrombocytopenia of medium severity $\left(100-50 \times 10^{9} / \mathrm{L}\right)$ before the operation was detected in 3 cases, mild thrombocytopenia (150 $100 \times 10^{9} / \mathrm{L}$ ) in 4 patients. The average PLT count prior to the surgery was $77.4 \pm 52.7 \times 10^{9} / \mathrm{L}$. On the $5^{\text {th }}-7^{\text {th }}$ day following the surgery the average PLT count was $317.1 \pm$ $119.6 \times 10^{9} / \mathrm{L}$; one month after the surgery $-264.5 \pm$ $221 \times 10^{9} / \mathrm{L}$; one year after the surgery $-187.2 \pm 148.8 \times$ $10 \% / \mathrm{L}$; the average count during the last follow-up visit on average $35.9 \pm 35.9$ months after the surgery was $120.2 \pm 160.5 \times 10^{9} / \mathrm{L}$. The pre-operative mean value of PLT count had increased in a statistically significant way in accordance with the independent pair selection t-test $(\mathrm{t}=3.087 ; \mathrm{p}=0.009)$, and in accordance with Wilcoxon signed-rank test $(z=2,202 ; p=0,028)$ compared to the mean value of PLT count, which was detected during the last follow-up visit on average $35.9 \pm 35.9$ months after the surgery.The physical condition of all patients prior the surgery was assessed in accordance with ASA classification (See Table 1). 
The values of perioperative indicators are included in Table 2

\begin{tabular}{|l|c|c|}
\hline \multicolumn{1}{|c|}{ Name } & $\begin{array}{c}\text { Maximum } \\
\text { fluctuations }\end{array}$ & $\begin{array}{c}\text { Average } \pm \\
\text { SD }\end{array}$ \\
\hline APTT (seconds) & $23.1-37.7$ & $23.9 \pm 11.1$ \\
\hline PI (\%) & $76-117$ & $82 \pm 39.0$ \\
\hline $\begin{array}{l}\text { Bleeding time (minutes'; } \\
\text { seconds") }\end{array}$ & $1^{\prime} 2^{\prime \prime}-5^{\prime} 48^{\prime \prime}$ & $2^{\prime} 32^{\prime \prime} \pm 1.7$ \\
\hline $\begin{array}{l}\text { The size of the spleen } \\
\text { before the operation (cm) }\end{array}$ & $8.3-14$ & $10.7 \pm 1.6$ \\
\hline Type of operation LS/CS & \multicolumn{2}{|c|}{$11 / 2$} \\
\hline Duration of CS ( minutes ) & $75-85$ & $80 \pm 7,0$ \\
\hline $\begin{array}{l}\text { Duration of LS ( minutes ) } \\
85-195\end{array}$ & $130.6 \pm$ \\
32.9
\end{tabular}

In 11 cases $(84.6 \%)$ laparoscopic splenectomy was performed, in 2 cases $(15.4 \%)$-conventional splenectomy. The duration of LS was $130.5 \pm 32.8$ minutes, duration of CS $-80 \pm 7.1$ minutes ( See Table 2 ). Blood loss during LS operation was $372.7 \pm 264.9$ millilitres (ml) . During CS - average $300 \pm 141.4 \mathrm{ml}$. During the operations 12 units of PLTM, 3 units of EM and 1 unit of FFP were transfused. The transfusion of PLTM during the operation did not differ statistically (applying $\chi^{2}$ method) depending upon the type of operation $\left(\chi^{2}=2.758 ; \mathrm{df}=3 ; \mathrm{p}=0.431\right)$. In the early post-operative period (ITN) 2 more PLTM units and 3 EM units were transfused.

Following the operation the majority of patients - 9 $(81 \%)$ were discharged on the $6^{\text {th }}-8^{\text {th }}$ day.

The average weight of the spleen after the operation $161.6 \pm 100.6$ grams. In all cases histological examination revealed changes typical of ITP - the histological pattern of the spleen

blotted, red pulp plethora.

In 3 cases complications developed following the operation. In one case a hematoma of the wound was detected following CS, in two cases - following LC trocar site hematomas. All wound hematomas gradually disappeared without specific treatment.

The average follow-up period was $35.9 \pm 35.9$ months (maximum fluctuations from 11 - 135) Analysis of variance (ANOVA) shows that the average age of cured patients

$34.6 \pm 9.8$ is statistically less significant than for those patients, who continue treatment and whose disease has transformed $(\mathrm{F}=7.327 ; \mathrm{p}=0.011)$.

\section{DISCUSSION}

The first splenectomy for treating haematological diseases was performed by Sutherland and Burghad in 1910 to treat hereditary spherocytosis. In 1916 Kaznelson reported on the use of splenectomy in treating ITP. ITP was treated surgically even up to 1958, when Damashek et.al. described the term "hypersplenism" and demonstrated the significance of GC in the treatment of chronic ITP and established it as the first line of treatment $(7,14)$. The side - effects of GC therapy and the development of minimally invasive surgical techniques facilitated the introduction of laparoscopic splenectomy in the treatment of ITP.

$50-80 \%$ of the patients are treated with splenectomy, and achieve full remission following the operation in $49-93 \%$ of the cases, therefore various perioperative predictive factors are searched that would allow predicting ITP outcome after the operation $(3,9$, $14,22,23)$. If 30 days after the operation and longer PLT count is $>150 \times 10^{9} / \mathrm{L}$ (more recent publications $\left.>100 \times 10^{9} / \mathrm{L}\right)$, without additional therapy, except cases, when GC dose is gradually cancelled after the operation, the remission is considered to be complete. Partial (incomplete) remission - PLT count is $50 \times 10^{9} / \mathrm{L}$ (or $30 \times 10^{9} / \mathrm{L}$ in more recent publications) or higher, detected 30 days after splenectomy and longer, with or without additional therapy, except those patients who have complete remission; no response to splenectomy (failure) - PLT count is $<50 \times 10^{9} / \mathrm{L}$ (in more recent publications $\left.<30 \times 10^{9} / \mathrm{L}\right)$, which has been detected 30 days after splenectomy with or without additional therapy (15).

One of the possible factors causing failure following the operation is the accessory spleen. During post mortems accessory spleen is found in $15-20 \%$ of population and their incidence is higher in patients with haematological diseases (14). The accessory spleen can have effect upon ITP treatment outcome following the operation $(9,14,23)$. In our study accessory spleen was detected in two cases prior to the operation during US and CT examinations, in both cases they were extirpated. During the operation and upon removal of the spleen from abdominal cavity atraumatic principles are complied with, to avoid injuring the spleen's capsule and prevent the spleen tissue contaminating surrounding tissue, thus avoiding the implantation of spleen tissue in the surrounding tissue. During repeated US and CT examinations after the operation no accessory spleens were detected in those patients with continuing ITP or whose disease had transformed into lymphoproliferative disorder (LPD). More recent research on the possibilities for diagnosing accessory spleen both prior and after the operation the use spiral CT and handheld gamma probe are mentioned (11, 18). It follows from the aforementioned that successful visualisation of accessory spleen tissue before the operation decreases the possibility of relapse after the operation. 
The clinical practical guidelines for laparoscopic splenectomy published by European Association of Endoscopic Surgeons in 2008 regard laparoscopic splenectomy as the "golden standard" in the treatment of ITP because of the unmodified or slightly modified size of the spleen (11). In our study the average size of the spleen was $10.7 \pm 1.6 \mathrm{~cm}$, i.e., the size of the spleen was unchanged (the normal longitudinal size of the spleen is $10-12 \mathrm{~cm}$ ) and in 9 cases laparoscopic splenectomy was performed. Literature reports that the type of operation does not affect the ITP outcome in a statistically significant way $(5,11)$. One of the most frequently assessed factors, which could influence ITP outcome following an operation is age $(3,7,8,14)$. In our study the mean value of the cured patients' age $34.6 \pm 9.8$ years is lower in a statistically significant way compared to those patients, who continue treatment or who have experienced transformation of the disease $(\mathrm{F}=$ 7.327; $p=0.011$ ). Kathkouda et al. mention that the age from 30 to 45 years is an independent predictive factor for successful outcome following the operation (14). Duperier et al. mention that patients, who are below 50 and who have undergone LS, have been successfully cured (7). It can be concluded that a more successful disease outcome following splenectomy can be predicted for younger patients.

Tsereteli et al. write that the duration of the disease prior to the operation is also one of the predictive factors, which should be considered for successful ITP outcome following splenectomy (22). In our study the mean value of the duration of the disease prior the operation (45 \pm 54.4 months) did not influence the disease outcome following the operation in a statistically significant way (ANOVA; $F=0.297 ; p=0.750$ ).

Duperier et al. mention that the disease outcome following splenectomy is influenced by PLT count before the operation - it should be $>70 \times 10^{9} / \mathrm{L}$ (7). In our study the mean value of PLT is $77.4 \times 10^{9} / \mathrm{L}$. The mean value of PLT prior to the operation does not influence ITP outcome after splenectomy in a statistically significant way (ANOVA, $F=0.429 ; p=0.663$ ). PLT is one of the parameters that can be adjusted before the operation. In our clinic the patients are prepared before the operation with PLTM transfusions, taking into consideration the general satus, clinical manifestations and coagulogram. However, currently no specific criteria have been defined for using PLTM while preparing for the operation because of the small number of ITP patients undergoing surgery.

It is mentioned in literature that the increase of PLT in the period from the first to the seventh day after the operation is a good predictive sign with regard to the ITP outcome following splenectomy $(2,5,14,15,17$, 23). Katkhouda et al. mention that if PTL count during the first three days following the operation stays within the range of $400-600 \times 10^{\%} / \mathrm{L}$, then the number of relapses is smaller (14). In 2004 Balague described that the patients with PTL count of $<100 \times 10^{9} / \mathrm{L}$ compared to patients with PTL count of $>100 \times 10^{9} / \mathrm{L}$ after the operation have a great probability of an unsuccessful disease outcome following splenectomy (2). J.- M. $\mathrm{Wu}$ describes two factors for reaching remission - the increase of PTL count immediately after LS $(p=0.01)$ and PTL count $\geq 100 \times 10^{9} / \mathrm{L}(\mathrm{p}=0,007)(23)$. K.Kojouri et al. in 2004 surveyed the literature available from Medline data base covering the period from 1966 to 2004 on the use of splenectomy in ITP treatment. The author concluded that PTL count increased after the operation, but different criteria and post-operative days are used to establish that (15). In our study the mean value of PTL count, which was detected before the operation $\left(77.4 \pm 52.7 \times 10^{9} / \mathrm{L}\right)$, had increased in a statistically significant way both in accordance with independent pair selection $t$-test $(t=3.087 ; p=0.009)$, and Wilcoxon signed-rank test $(\mathrm{z}=2.202 ; \mathrm{p}=0.028)$ compared with the mean value of PTL detected during the last follow up visit $\left(120.2 \pm 160.5 \times 10^{9} / \mathrm{L}\right)$. However, PTL count before the operation and PTL count on the $7^{\text {th }}$ day does not influence the disease outcome in a statistically significant way (ANOVA; $\mathrm{F}=0.429 ; \mathrm{p}=0.663$ and $\mathrm{F}=$ $0.950 ; p=0.41)$.

\section{CONCLUSIONS}

The performed research allows concluding that the decisive factors in successful ITP outcome after the operation are the following: 1) in patients, who have undergone the operation in a relatively younger age ( $34.6 \pm 9.8$ years) the disease outcome is more successful during the follow - up period $-35.9 \pm 35.9$ months $(\mathrm{F}=$ $7.327 ; p=0.011) ; 2$ ) the visualisation and removal of the accessory spleen decreases the probability of relapse.

\section{Conflict of interest: None}

\section{REFERENCES}

1. Arnold DM, Dentali F, Crowther MA, et al. Systematic review: Efficacy and safety of rituximab for adults with idiopathic thrombocytopenic purpura // Ann Intern Med, 2007; 146:25 - 33

2. Balague C, Targarona EM, Cerdan G, Novell J, Montero O, Bendahan G, Garcia A, Pey A, Vela S, Diaz M, Trias M. Long-term outcome after laparoscopic splenectomy related to hematologic diagnosis // Surg Endosc, 2004;18(8):1283 - 1287

3. Balague C, Vela S, Targarona EM, Gich IJ, Muniz E, D’Ambra A, Pey A, Monllau V, Ascaso E, Martinez C, Garriga J, Trias M. Predictive factors for successful laparoscopic splenectomy in immune thrombocytopenic purpura: study of clinical and laboratory data // Surg Endosc, 2006 Aug; 20(8): $1208-1213$

4. British Committee for Standards in Haematology General Haematology Task Force. Guidelines for the investigation and management of idiopathic thrombocytopenic purpura in adults, children and in pregnancy // Br J of Haematol, 2003; 120: $574-596$ 
5. Cordera F, Long KH, Nagorney DM, McMurtry EK, Schleck C, Ilstrup D, Donohue JH. Open versus laparoscopic splenectomy for idiopathic thrombocytopenic purpura: clinical and economic analysis // Surgery, 2003; 134(1):45 - 52

6. Cortelazzo S, Finazzi G, Buelli $M$, et al. High risk of severe bleeding in aged patients with chronic idiopathic thrombocytopenic purpura // Blood, 1991;77:31

7. Duperier T, Brody F, Felsher J, Walsh RM, Rosen $\mathrm{M}$, Ponsky J. Predictive factors for successful laparoscopic splenectomy in patients with immune thrombocytopenic purpura // Arch Surg, 2004; 139(1):61 - 66

8. Fabris F, Tassan T, Ramon R, Carraro G, Randi ML, Luzzatto G, Moschino P, Girolami A. Age as the major predictive factor of long-term response to splenectomy in immune thrombocytopenic purpura // Br J Haematol, 2001; 1 12: 637 - 640

9. Gadenstätter M, Lamprecht B, Klingler A, Wetscher GJ, Greil R, Schmid T. Splenectomy versus medical treatmentforidiopathicthrombocytopenicpurpura // Am J Surg, 2002; 184(6):606 - 609

10. George JN, Raskob GE, Vesely SK, et al. Initial management of immunethrombocytopenic purpura in adults: A randomized controlled trial comparing intermittent anti-D with routine care // Am J Hematol, 2003;74:161 - 169

11. Habermalz B, Sauerland S, Decker G, Delaitre B, Gigot JF, Leandros E, Lechner K, Rhodes M, Silecchia G, Szold A, Targarona E, Torelli $P$, Neugebauer E. Laparoscopic splenectomy: the clinical practice guidelines of the European Association for Endoscopic Surgery (EAES) // Surg Endosc, 2008; 22(4):821 - 848

12. James P. Dolan, Brett C. Sheppard, Thomas G. DeLoughery. Splenectomy for immune thrombocytopenic purpura: Surgery for the $21 \mathrm{st}$ century // Am J Hematol, 2008; 83:93 - 96

13. Julia A, Araguas C, Rossello J, Bueno J, Domenech P, Olona M, Guardia R, Petit J, Flores A. Lack of useful clinical predictors of response to splenectomy in patients with chronic idiopathic thrombocytopenic purpura // Br J Haematol, 1990; 76(2):250-255

14. Katkhouda N, Manhas S, Umbach TW, Kaiser AM. Laparoscopic splenectomy // J Laparoendosc Adv Surg Tech A, 2001;11(6):383 - 390

15. K.Kojuri, S.Vasely, D.R. Terrell, J.N.George. Splenectomy for adult patients with idiopathic thrombocytopenic purpura:a systematic review to asses long-term platelet count responses, prediction of response, and surgical complications // Blood, 2004;104(9):2623 - 2634
16. Kumar S., Diehn FE., Gertz MA. Tefferi A. Spleneclomy for immune thrombocytopenic purpura: long-term results and treatment of postsplenectomy relapses // Ann Hematol 2002; $81: 312-319$

17. L. R. Khan, S. J. Nixon. Laparoscopic splenectomy is a better treatment for adult ITP than steroids it should be used earlier in patient management. Conclusions of a ten-year follow-up study // Surgeon; 2007; 5(1):3-8

18. Reyhan Diz-Kucukkaya, MD; Amy Geddis, MD, PhD; Jose A. Lopez, MD. Part XII. Hemostasis \& Thrombosis, Chapter 119 Thrombocytopenia // Marshall A. Lichtman, Thomas J. Kipps, Uri Seligsohn, Kenneth Kaushansky, Josef T. Prchal. Williams Hematology, 8e. The McGraw-Hill Companies, Inc.; 2010 . $8^{\text {th }}$ DVD format.

19. Park A., Marcaccio M., Sternbach M., Witzke D., Fitzgerald P. Laparascopic vs open splenectomy // Arch Surg, 1999; 134:1263 - 1269

20. Sampath S, Meneghetti AT, MacFarlane JK, Nguyen NH, Benny WB, Panton ON. An 18-year review of open and laparoscopic splenectomy for idiopathic thrombocytopenic purpura // Am J Surg, 2007; $193(5): 580-583$

21. Stanton CJ. Laparoscopic spleneetomy for idiopathic thrombotytopenic purpura (ITP): a fiveyear experience // Surg Endosc, 1999; 13:1083 1086

22. Tsereteli Z, Smith CD, Branum GD, Galloway JR, Amerson RJ, Chakaraborty H, Hunter JG. Are the favorable outcomes of splenectomy predictable inpatients with idiopathic thrombocytopenic purpura (ITP)? // Surg Endosc, 2001; 15(12): $1386-1389$

23. Wu JM, Lai IR, Yuan RH, Yu SC. Laparoscopic splenectomy for idiopathic thrombocytopenic purpura // Am J Surg, 2004; 187(6):720 - 723

\section{Address:}

Ieva Vidmane-Ozola

State Share Company Riga Eastern Clinical University Hospital, Clinic "Linezers"

6, Linezera Street, Riga

Latvia LV-1006

E-mail: ievid@yahoo.com 